\title{
Linking bacterioplankton community structures to environmental state variables and phytoplankton assemblages in two South Carolina salt marsh estuaries
}

\author{
Wes Johnson ${ }^{1, *}$, Alan J. Lewitus ${ }^{2,3}$, Madilyn Fletcher ${ }^{1,2}$ \\ ${ }^{1}$ Marine Science Progam, EWS Rm 603, University of South Carolina, Columbia, 29208 South Carolina, USA \\ ${ }^{2}$ Belle W. Baruch Institute for Marine and Coastal Sciences, EWS Rm 604, University of South Carolina, Columbia, \\ 29208 South Carolina, USA
}

${ }^{3}$ Present address: NOAA Center for Sponsored Coastal Ocean Research, 1501 East West Highway, Silver Spring, 20910 Maryland, USA

\begin{abstract}
Microorganisms are among the most important organisms to the ecology of salt marsh estuaries; however, fundamental questions regarding their distribution, environmental controls, and interactions with phytoplankton remain unanswered. We used denaturing gradient gel electrophoresis (DGGE) of bacterial rRNA genes and high performance liquid chromatography (HPLC) of phytoplankton photopigments to characterize planktonic communities from the Ashepoo, Combahee, and Edisto (ACE) Basin and North Inlet (NI) estuaries on the South Carolina coast, USA. Multivariate comparisons of the planktonic community profiles revealed that the 2 estuaries supported distinct bacterial communities. Furthermore, bacterial communities in both systems were partitioned into separate particle-associated (PA) and free-living (FL) components. Differences in bacterial populations were also observed along the salinity gradient within each system. Comparisons of water physicochemistry with bacterial profiles indicated significant correlation of PA bacterial community structures with temperature, salinity, organic carbon, total phosphorus, and ammonium, whereas FL communities were affected by nitrate, ammonium, total phosphorus and orthophosphate. PA bacterioplankton community structures were also associated with diatoms, dinoflagellates, haptophytes and cryptophytes, while FL assemblages corresponded to prasinophytes, chlorophytes, and cyanobacteria. Comparisons between estuaries further demonstrated that ACE Basin communities were mostly associated with the same pigments as PA samples, and that NI assemblages correlated with FLassociated phytoplankton, suggesting different trophodynamics of particles in the 2 systems.
\end{abstract}

KEY WORDS: Bacteria $\cdot$ Phytoplankton $\cdot$ Community structure $\cdot$ HPLC $\cdot$ DGGE $\cdot$ Salt marsh estuary

\section{INTRODUCTION}

Microorganisms in salt marsh estuarine ecosystems perform critical functions in the processing of organic matter and the mineralization of important nutrients. The diagenesis of macrophyte biomass, the uptake of nutrients by bacteria, and the subsequent transfer to higher trophic levels through grazing form the basis of the complex heterotrophic food webs that support much of the secondary production in these estuaries. Primary pro- duction in estuaries also depends upon microbial processes because bacteria fix and remineralize the inorganic nutrients that limit phytoplankton growth and production. The importance of these bacterial processes to the trophic interactions and overall ecology of aquatic systems has inspired extensive study of bacterial communities. Despite this attention, fundamental questions remain regarding bacterial community distribution and the factors that contribute to the structuring of bacterial assemblages in estuarine habitats. 
In some aquatic ecosystems abiotic factors such as riverine input, salinity, temperature, or availability of nutrients have been shown to control the composition of the plankton communities present (Lind \& Barcena 2003, Smith \& Kemp 2003, Kirchman et al. 2004). In estuarine systems in particular, phytoplankton and bacterioplankton productivity and taxonomic composition have been shown to be sensitive to changes in nutrient concentrations (Noble et al. 1997, Seitzinger \& Sanders 1999, Kirchman et al. 2004, Lagus et al. 2004). However, other research has demonstrated that the structure of complex, natural communities as well as relatively simple bacterial assemblages may remain unchanged when exposed to significant shifts in nutrient chemistry (Fernandez et al. 1999, Piceno \& Lovell 2000, Lovell et al. 2001, LaPara et al. 2002). The importance of such bottom-up controls on community composition is often assumed for ecosystems; however, owing to the inherent complexity of bacterial communities and the practical difficulty of making comparisons of small-scale phenomena across large spatial scales, such controls are difficult to determine. Additionally, the abiotic factors that influence community dynamics appear to vary among different ecosystems, and among different zones within an ecosystem (Noble et al. 2003, Pinhassi et al. 2003, Bordalo \& Vieira 2005).

The composition of bacterioplankton populations is also influenced by the composition of phytoplankton communities. In lakes, estuaries, and the marine environment, bacterial production, function, and community composition change as phytoplankton blooms form, develop, and then collapse (Kirchman et al. 1991, Fandino et al. 2001, Riemann \& Winding 2001). Furthermore, these changes appear to vary with respect to the species that dominates the bloom (Pinhassi et al. 2004), suggesting specific interactions between phytoplankton and bacteria, which may remain even in the absence of a bloom event.

Until recently, the ability to measure and interpret such community dynamics in situ has been limited by the complexity of bacterial communities and the difficulties and biases associated with culturing and identifying organisms. However, molecular methods developed in the past 2 decades have allowed for culture-independent comparisons between communities. In particular, denaturing gradient gel electrophoresis (DGGE) of 16S rRNA gene fragments has come to the forefront of bacterial community structure analysis (Boon et al. 2002). This technique allows for the simultaneous comparison of multiple samples by creating 'fingerprints' of the bacterial community, which can be compared visually. The differences in these banding patterns indicate differences in the composition of the communities from which they are generated. This technique has been used successfully to characterize bacterial community diversity and composition in a number of aquatic ecosystems, including estuaries (Trimmer et al. 1997, Hollibaugh et al. 2000, Sekiguchi et al. 2002, Wetz et al. 2002, Selje \& Simon 2003, Lassen et al. 2004). Additionally, bands in these patterns can be excised and sequenced to identify the taxa that are observed in the gel images.

The composition and successional dynamics of phytoplankton communities have been similarly difficult to assess as a result of the high species diversity, multiple life stages, interspecific morphologies, and complex interactions between community members and their environment. High performance liquid chromatography (HPLC) of photopigments has been recently used in numerous studies to generate a composite profile of the phytoplankton community (Higgins \& Mackey 2000, Pinckney et al. 2001, Rodriguez et al. 2002). Group-specific pigments in particular offer information on the relative abundance of phytoplankton taxa within the community, while the relative amounts of all pigments measured give a broad picture of the whole community.

In the present study, we used both HPLC of photopigments collected in the summer of 2000 by Noble et al. (2003) and DGGE of bacterial 16S rRNA genes to compare communities within and between 2 estuaries on the South Carolina coast, USA. The primary objectives of this study were to (1) assess in situ patterns of bacterial community distribution within and between 2 pristine salt marsh estuaries, (2) determine the ecological factors that control phytoplankton and bacterial community structures, and (3) identify potential associations between phytoplankton and bacterial community structures in these ecosystems. As the interface between terrestrial and marine ecosystems, estuaries exhibit distinct spatial gradients of chemical and physical characteristics on a landscape scale. We hypothesized that bacterial community composition will differ and vary according to differences in environmental state variables along the chemical gradients. Furthermore, we expected that differences in phytoplankton community compositions will correspond to distinct and predictable shifts in the composition of bacterial assemblages.

\section{MATERIALS AND METHODS}

Site description. The Ashepoo, Combahee, and Edisto (ACE) Basin and the North Inlet (NI) systems are located ca. $100 \mathrm{~km}$ apart on the coast of South Carolina. The 2 estuaries are similar in temperature, salinity, tidal range and tidal frequency, and, as reserve sites of the National Estuarine Research Reserve System, both drainages are almost entirely undeveloped. The ACE Basin has a relatively large watershed of 
approximately $8000 \mathrm{~km}^{2}$ that drains into 3 major rivers, the Ashepoo, the Combahee, and the Edisto. The freshwater input of these rivers to the system is roughly $41 \%$ of the total volume of the estuary (Dame et al. 2000). In contrast, NI is tidally dominated and features very little freshwater input. Morris (2000) estimated the freshwater input to be $3 \%$ of the total tidal volume. These inter-estuary differences in freshwater cycling result in variations in nutrient dynamics. The terrestrial input in the ACE Basin system leads to higher concentrations of dissolved nutrients than in NI, where available nutrients are predominantly derived from sediment processes and the influx of seawater.

Four sampling stations were selected within each estuary to reflect the salinity gradient in each system (Fig. 1). ACE Stn 1 was located at the outflow of a small tributary into the Edisto River. Stn 2 was located in St. Pierre Creek, and Stn 3 was located at the confluence of St. Pierre Creek and the Edisto River. The most seaward station (Stn 4) was located on the eastern margin of St. Helena Sound. NI Stn 1 was a tributary of Crabhaul Creek, Stn 2 was at Oyster Landing, Stn 3 was located in the main body of Clambank Creek, and Stn 4 was in Town Creek.

Sample collection. Samples were collected from each station monthly from April to October 2000 beginning at solar noon during the spring tide. Temperature,
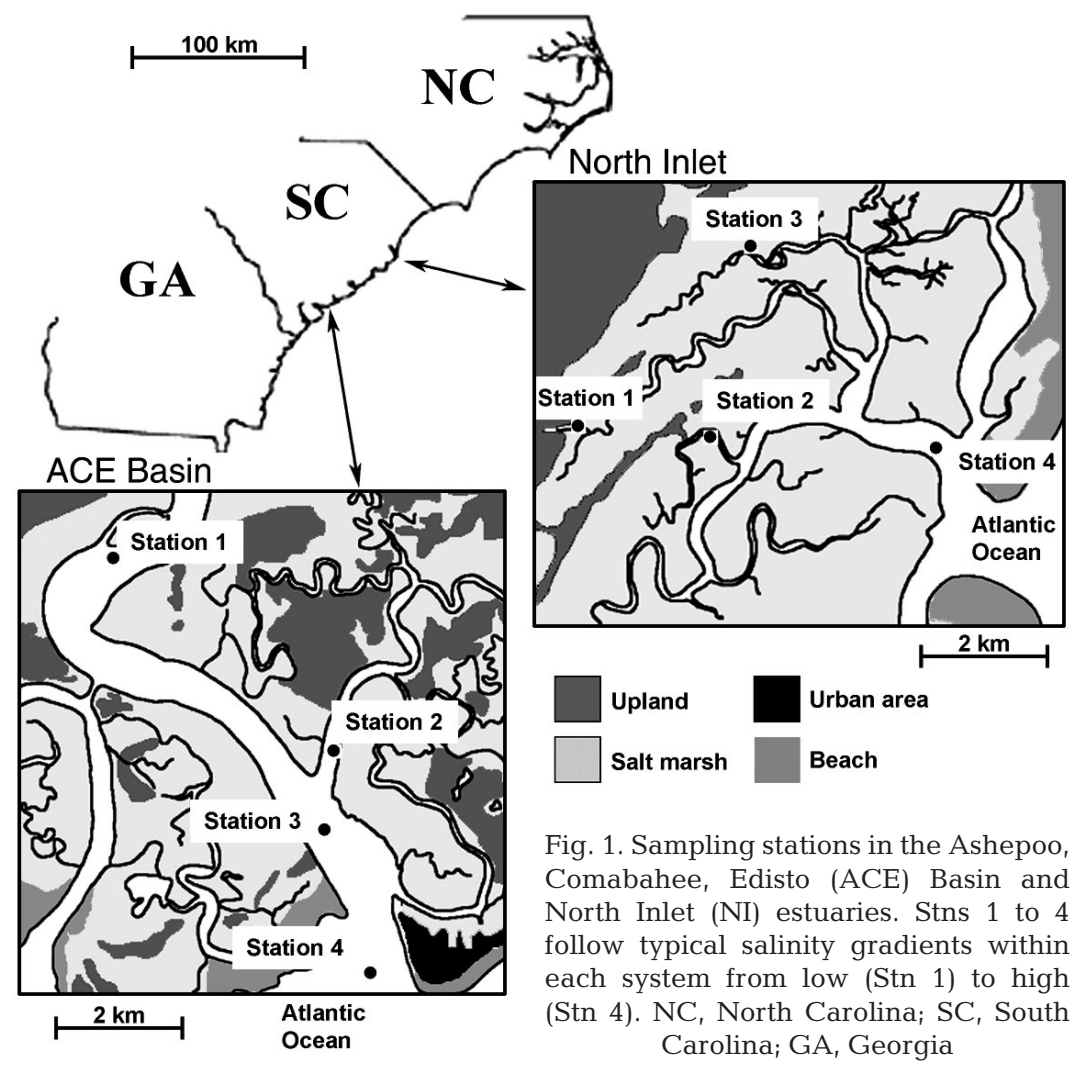

Fig. 1. Sampling stations in the Ashepoo, Comabahee, Edisto (ACE) Basin and North Inlet (NI) estuaries. Stns 1 to 4 follow typical salinity gradients within each system from low (Stn 1) to high (Stn 4). NC, North Carolina; SC, South Carolina; GA, Georgia salinity, and pH were measured in situ using a Hydrolab datasonde (Hydrolab-Hach Company), and water samples for chemical analyses, bacterial counts, and photopigment determination were collected in triplicate from $\sim 30 \mathrm{~cm}$ depth at each site in sterile $1 \mathrm{l}$ screw top jars. Water for bacterial community analysis was collected in duplicate 81 containers with sealing lids. All water samples were stored in the dark on ice until processed (3 h maximum).

Bacterial communities were separated into particleassociated (PA) and free-living (FL) fractions by sequentially filtering through a $3 \mu \mathrm{m}$ pore-size polycarbonate filter (47 $\mathrm{mm}$; Millipore), and then by passing the filtrate through a $0.22 \mu \mathrm{m}$ pore-size Sterivex filter (Millipore), following the protocol of Bidle \& Fletcher (1995). These filters were placed immediately on dry ice and stored at $-80^{\circ} \mathrm{C}$ until processed.

Bacterial abundance. Direct bacterial cell counts were performed by fixing $50 \mathrm{ml}$ of each water sample in glutaraldehyde (5\% final concentration w/v). A subsample ( $2 \mathrm{ml}$ ) of each fixed sample was filtered through a sterile $3 \mu \mathrm{m}$ pore-size polycarbonate filter, and $1 \mathrm{ml}$ of the filtrate was stained with $50 \mu$ of $10 \mu \mathrm{M}$ Sytox Green nucleic acid stain (Molecular Probes) for $30 \mathrm{~min}$. Due to high background fluorescence and the opacity of the particles themselves, accurate direct counts of PA organisms were not possible, and are absent from this study.

Stained samples were diluted in $5 \mathrm{ml}$ phosphate-buffered saline $(0.1 \mathrm{M}$ $\mathrm{NaCl}, 3 \mathrm{mM} \mathrm{K} \mathrm{HPO}_{4}, \mathrm{pH}$ 7.2) and filtered at $250 \mathrm{~mm} \mathrm{Hg}$ vacuum onto black polycarbonate filters with $0.22 \mu \mathrm{m}$ pore-size (25 $\mathrm{mm}$; Millipore). Filters were mounted onto glass microscope slides with $10 \mu \mathrm{l}$ DABCOglycerol (1,4-diazobicyclo[2.2.2]octane) to stabilize fluorescence (Lovell et al. 1999). Filters were viewed at $600 \times$ magnification using an Olympus BX40 microscope equipped with a BX-FLA (Olympus) reflected light fluorescence attachment and an acridine orange filter cube set (488 nm excitation, $630 \mathrm{~nm}$ emission). Images of the filters were captured using a digital camera driven by the V5 acquire module of IPLab Spectrum 3.1 image analysis software (Scanalytics). Cells were enumerated by segmenting and counting using the IPLab Spectrum software as recommended by the software manufacturer.

Water chemistry. Concentrations of nitrate + nitrite (NN), ammonium $\left(\mathrm{NH}_{4}\right)$, total nitrogen (TN), total dis- 
solved nitrogen (TDN), orthophosphate $\left(\mathrm{PO}_{4}\right)$, total phosphorus (TP), total dissolved phosphorus (TDP), and silicate $(\mathrm{Si})$ were measured with a Technicon Autoanalyzer (Pulse Instrumentation) according to the manufacturer's instructions. Dissolved organic carbon (DOC) was measured using a Shimadzu TOC-500 carbon analyzer following filtration through $0.22 \mu \mathrm{m}$ polypropylene filters (Millipore). Statistical analyses of chemical data were conducted by ANOVA and multiple regression analysis using the Statistical Analysis Software package (SAS).

HPLC. HPLC was used to detect 18 pigments that can be used as indicators of specific phytoplankton taxa (Table 1). Pigments were extracted in $100 \%$ acetone using a tissue grinder. The resulting slurry was then filtered through a Teflon HPLC syringe filter $(0.45 \mu \mathrm{m})$. HPLC was performed according to a protocol modified from Van Heukelem \& Thomas (2001). Briefly, pigments were separated using a Beckman System Gold HPLC with an external column heater, 125 solvent module dual pump, and photodiode array detector with deuterium lamp (monitoring $450 \mathrm{~nm}$ ), using temperature-control and a polymeric column. Pigment standards were obtained from L. Van Heukelem (Horn Point Laboratory, University of Maryland). For composition analysis, all pigment concentra-

Table 1. Photopigments used for phytoplankton community analysis and their corresponding taxa as indicated by Noble et al. (2003) and Paerl et al. (2003). 19'-but: 19'-butanoyloxyfucoxanthin; 19'-hex: 19'-hexanoyloxyfucoxanthin

\begin{tabular}{|c|c|}
\hline Photopigment & Associated taxa \\
\hline Chl a & All photosynthetic algae \\
\hline Chl $b$ & Chlorophytes, prasinophytes \\
\hline Chl $c_{1}$ & $\begin{array}{l}\text { Diatoms, dinoflagellates, } \\
\text { prymnesiophytes, cryptophytes }\end{array}$ \\
\hline $\mathrm{Chl} C_{2}$ & $\begin{array}{l}\text { Diatoms, dinoflagellates, } \\
\text { prymnesiophytes, cryptophytes }\end{array}$ \\
\hline Fucoxanthin & $\begin{array}{l}\text { Bacillariophytes, prymnesiophytes, } \\
\text { cryptophyes }\end{array}$ \\
\hline Prasnioxanthin & Some prasinophytes \\
\hline Violaxanthin & $\begin{array}{l}\text { Chlorophytes, prasinophytes, } \\
\text { eustigmatophytes }\end{array}$ \\
\hline Zeaxanthin & $\begin{array}{l}\text { Cyanobacteria, prochlorophytes, } \\
\text { rhodophytes, chlorophytes }\end{array}$ \\
\hline Neoxanthin & Chlorophytes \\
\hline Diatoxanthin & Diatoms, prymnesiophytes \\
\hline Diadinoxanthin & $\begin{array}{l}\text { Diatoms, prymnesiophytes, chrysophytes, } \\
\text { euglenophytes }\end{array}$ \\
\hline Alloxanthin & Cryptophytes \\
\hline Peridinin & Dinoflagellates \\
\hline $19^{\prime}$-but & $\begin{array}{l}\text { Some prymnesiophytes, some } \\
\text { dinoflagellates }\end{array}$ \\
\hline $19^{\prime}$-hex & Prymnesiophytes, chrysophytes \\
\hline Lutein & Chlorophytes \\
\hline Canthaxanthin & Benthic cyanobacteria \\
\hline Carotenes & Most photosynthetic algae \\
\hline
\end{tabular}

tions were normalized to the chl a concentration from each sample. Phytoplankton community profiles were compared by cluster analysis as described by Noble et al. (2003). Additional analysis of community structures and their relationships to environmental state variables were performed using canonical correspondence analysis (CCA) in the Multi-Variate Statistical Package (MVSP; Kovach Computing Services).

DNA extraction. Community DNA was extracted from PA and FL samples using a modified nucleic acid extraction protocol described by Bidle \& Fletcher (1995). FL cells were lysed directly in the Sterivex filter cartridges using $1 \%$ sodium dodecyl sulfate (SDS) solution in TE (10 mM TRIS, 1 mM EDTA, pH 7.9), and heated to $65^{\circ} \mathrm{C}$ for $30 \mathrm{~min}$. The solution was drawn out and extracted once with an equal volume of saturated phenol ( $\mathrm{pH} 7.9$ ), and once with an equal volume of chloroform. PA cells were lysed by cutting the $3 \mu \mathrm{m}$ filters into small pieces using a sterile scalpel and heating them to $65^{\circ} \mathrm{C}$ in $3 \mathrm{ml}$ of $1 \%$ SDS in TE for $30 \mathrm{~min}$. The solution was then drawn off using a pipette and phenol/chloroform extracted as above. DNA solutions were precipitated in an equal volume of ethanol and centrifuged for $30 \mathrm{~min}$ at $10000 \times \mathrm{g}$. The pellets were air-dried and resuspended in $100 \mu \mathrm{TE}$; 1:10 dilutions of the samples were used as working stocks for polymerase chain reaction (PCR)/DGGE and the remaining samples were preserved in $50 \%$ ethanol/TE at $-20^{\circ} \mathrm{C}$.

PCR/DGGE. A 195 bp fragment of the hyper-variable V3 region of the 16S rRNA gene was amplified using the 341f, 5'-CGCCCGCCGCGCCCCGCGCC CGGCCCGCCGCCCCCGCCCCCCTACGGGAGGC AGCAG-3' and 534r, 5'-ATTACCGCGGCTGCTGG-3' oligonucleotide primers as described by Muyzer et al. (1993). The underlined portion of the forward primer is a $40 \mathrm{bp}$ G/C clamp, described by Ferris et al. (1996). Each sample was amplified in 4 separate $25 \mu \mathrm{l}$ reactions, which were pooled before running on DGGE. Each $25 \mu \mathrm{l}$ reaction contained $1 \mu \mathrm{l}$ of the template DNA described above or $25 \mathrm{ng}$ of purified genomic DNA (for markers), 0.2 U Taq DNA polymerase (Promega), $2.5 \mu \mathrm{l}$ of $10 \times$ reaction buffer supplied with the polymerase by the manufacturer, $200 \mu \mathrm{M}$ final concentration each of deoxyribonucleoside triphosphate (dNTP), $0.5 \mathrm{pmol}$ $\mu^{-1}$ of each primer, $0.4 \mu \mathrm{g} \mathrm{ul}^{-1} \mathrm{BSA}$, and $1.5 \mathrm{mM}$ $\mathrm{MgCl}_{2}$. Reactions were run in a MJ Research PTC-200 thermal cycler equipped with a heated lid using a touchdown protocol with an initial denaturing step at $94^{\circ} \mathrm{C}$ for 3 min followed by 20 cycles of $94^{\circ} \mathrm{C}$ for $60 \mathrm{~s}$, $62^{\circ} \mathrm{C}$ for $30 \mathrm{~s}$ (decreasing by $0.5^{\circ} \mathrm{C}$ cycle $^{-1}$ ), and $72^{\circ} \mathrm{C}$ for $30 \mathrm{~s}$. An additional $15 \mathrm{cycles}$ of $94^{\circ} \mathrm{C}$ for $30 \mathrm{~s}, 52^{\circ} \mathrm{C}$ for $30 \mathrm{~s}$, and $72^{\circ} \mathrm{C}$ for $30 \mathrm{~s}$ were performed followed by a final extension of $72^{\circ} \mathrm{C}$ for $4 \mathrm{~min}$. All reactions were run on $2 \%$ agarose to confirm adequate amplification, and samples were ethanol precipitated and centri- 
fuged and the pellets air-dried. Amplimers were resuspended in $10 \mu \mathrm{l}$ TE and $5 \mu$ l loading dye $(0.25 \%$ bromophenol blue, $0.25 \%$ xylene cyanol FF, $40 \%$ sucrose) for loading into DGGE.

DGGE was performed on polyacrylamide gels containing a double gradient: 8 to $10 \%$ acrylamide/bisacrylamide (37.5:1) and 54 to $70 \%$ denaturants with a stacking gel of $8 \%$ acrylamide/bis-acrylamide containing no denaturants. Samples were loaded onto preheated $\left(60^{\circ} \mathrm{C}\right)$ gels in $7 \mathrm{l}$ of TAE buffer $(0.04 \mathrm{M}$ Tris, $0.02 \mathrm{M}$ acetic acid, $1 \mathrm{mM}$ EDTA) in a BioRad DCode apparatus. Gels were run at $60^{\circ} \mathrm{C}$ at $100 \mathrm{~V}$ for $21 \mathrm{~h}$, stained in $1 \times$ ethidium bromide in TAE for 30 min, destained twice in deionized water for $10 \mathrm{~min}$, and imaged on a BioRad GelDoc 2000 transilluminator. Images were captured by a digital camera using the VG5 acquire module of the IPLab Spectrum image analysis software package. Statistical analyses of DGGE results were performed by first scoring the banding patterns using the GelCompar 4.0 software package (Applied Maths). Band positions were normalized to a Bacillus licheniformis 16S rRNA gene marker (3 lanes per gel), and the intensity of each band was measured. Intensity values for every band were normalized to the maximum intensity in the respective lane. For simultaneous comparisons across all samples, 45 potential band positions were used to generate an operational community unit (OCU) for each sample. Because DGGE analysis is subject to PCR bias (Hansen et al. 1998, Stephen et al. 1998, Kanagawa 2003, Lueders \& Friedrich 2003), each OCU was constructed by converting the intensity measurements of the brightest 14 bands (the minimum number of bands observed in any single sample) to a binary score indicating absence (0) or presence (1) of a band at each position in a gel lane. The resulting data were analyzed using the unweighted pairwise group method analysis (UPGMA) protocol in the MVSP. Similarity matrices were calculated using Jaccard's coefficient. The resulting similarity matrices were analyzed for differences using a Monte-Carlo permutation significance test described by Kropf et al. (2004). Briefly, comparisons were made of within- and between-group correlations using the test statistic $d=$ $r_{\text {within }}-r_{\text {between, }}$ where $r_{\text {within }}$ and $r_{\text {between }}$ are the arithmetic mean over all Jaccard coefficients within and between groups, respectively. In the permutation test, values in the similarity matrices were moved randomly within the matrix and the effect on $d$ was measured. If the random movement of elements among groups did not systematically decrease the value of $d$, then the null hypothesis of $d=0$ is rejected. For more detailed description of this statistical method, refer to Kropf et al. (2004). In addition, CCA was performed using the PA/FL fractions as nominal environmental variables, as described by Rooney-Varga et al. (2005). Here we assigned PA samples a value of 0 and FL samples a value of 1 . CCA was also applied to pigment profiles, DGGE banding patterns, and environmental data simultaneously to examine direct relationships between state variables and community profiles.

Band sequencing. Prominent bands that appear to align across multiple gels were sequenced from each gel to assess the number of sequences present in the bands and to confirm the correct alignment of the band positions for all gels used in this study. The positions of the excised bands are shown in Fig. 2. Bands from each sample lane in which a particular band appeared were excised directly from denaturing gradient gels using a wide-orifice pipette tip and stored in $50 \mu \mathrm{l} \mathrm{TE}$ at $4^{\circ} \mathrm{C}$. The band products were reamplified and separated by DGGE to confirm their positions on the gels and to disqualify heteroduplexes for cloning. Selected band products were then PCR-amplified using the same reaction conditions as the community DNA amplifications, except that the forward primer did not include the $40 \mathrm{bp}$ G/C clamp. The resulting amplimers were cloned into JM109 competent cells using the pGEM-T vector kit (Promega) following the protocol of the manufacturer. Ten colonies from each band amplification were selected and transferred to LB/Ampicillin plates and grown at $37^{\circ} \mathrm{C}$ overnight before plasmid isolation. pGEM plasmids were recovered from 5 colonies from each of the original band amplimers by heating cells at $100^{\circ} \mathrm{C}$ for $10 \mathrm{~min}$ followed by centrifugation at $10000 \times g$ for $30 \mathrm{~s}$. Samples were immediately put on ice, and $15 \mu$ of the supernatant was used as template for PCR amplification of the insert with T7 and Sp6 primers. Inserts were amplified in $25 \mu \mathrm{l}$ reactions containing $2.5 \mu \mathrm{l} 10 \times$ reaction buffer, $100 \mu \mathrm{M}$ final concentration of each dNTP, $1.5 \mathrm{mM}$ final concentration $\mathrm{MgCl}, 12.5$ pmol each primer, and 0.1 U Taq polymerase (Promega). Reactions were run in a $\mathrm{MJ}$ Research thermal cycler by the following protocol: initial denaturing at $94^{\circ} \mathrm{C}$ for 2 min followed by 30 cycles of $94^{\circ} \mathrm{C}, 47^{\circ} \mathrm{C}$, then $72^{\circ} \mathrm{C}$ for $30 \mathrm{~s}$ each, and a final extension at $72^{\circ} \mathrm{C}$ for $2 \mathrm{~min}$. The resulting amplimers were digested with HaeIII and MspI and separated on agarose to determine the number of different sequences comprising each band. Each unique restriction digest pattern from every band was used in cycle sequence reactions using the BigDye v3.1 system (Applied Biosystems) following the manufacturer's instructions. Sequences were obtained using an ABI autosequencer, and aligned using BioEdit software (Ibis Therapeutics). Sequences were compared to existing sequences in the GenBank database to confirm that bands represented organisms likely to be found in salt marsh estuaries. 


\section{RESULTS}

\section{Water chemistry}

The water chemistry results from both estuaries are summarized in Table 2. Grand means indicated greater concentrations of NN, TP, TDP, and $\mathrm{PO}_{4}$ in ACE than in NI $(\alpha=0.05)$. In contrast, $\mathrm{NH}_{4}$ concentration and salinity were both significantly greater in NI samples than in ACE samples. Within the ACE estuary, salinity followed the expected gradient, with the lowest salinities recorded at Stn 1 and increasing in the seaward direction to Stn 4 for all months sampled (Table 2). In contrast, the patterns of salinity in NI were only consistent with predicted gradient in samples collected in April, August, and September (Table 2). For all other months, salinity remained essentially unchanged from station to station.

Within each estuary, the nutrient patterns typically followed the salinity gradient, with lower nutrient concentrations generally found in the seaward direction, presumably as a result of dilution in seawater (Table 2). These trends were more apparent in the ACE Basin, where concentrations of DOC, TN, NN, $\mathrm{NH}_{4}$, and TP were all negatively correlated with salinity $(\alpha=0.05)$, exhibiting a significant decrease in the seaward direction. TDP concentration and $\mathrm{pH}$ were both positively correlated with salinity in ACE samples. NI samples revealed similar patterns in nutrient distributions, with DOC, $\mathrm{NN}$, and $\mathrm{NH}_{4}$ negatively correlated with salinity and $\mathrm{PO}_{4}$ directly correlated with salinity. These patterns of nutrient distribution are indicative of riverine influence in each estuary.
NI samples from August were collected a few hours following a rain event, which is reflected in the anomalous water chemistry data from Stn 1. Salinity at Stn 1 averaged 33.3 psu throughout the sampling period, but fell to $2 \mathrm{psu}$ in samples from that time point. $\mathrm{PO}_{4}$ concentrations were also significantly lower in this sample than at any point in the sampling season. In contrast, concentrations of $\mathrm{NH}_{4}$ and DOC at NI Stn 1 were significantly higher in August than in any other month.

\section{Bacterial abundance}

Distributions of FL bacterial abundance of ACE and NI samples are represented in Fig. 3. Direct counts of FL cells from ACE samples were significantly higher than those from NI samples in April, May and October $(p<0.0001)$. This pattern was reversed in July, when NI cell counts were significantly higher than those from ACE ( $p=0.0120)$. Within both estuaries bacterial abundance generally decreased with increasing salinity; however, this trend is significant only for ACE samples $(\alpha=0.05)$.

\section{Photopigments}

The photopigment data presented here are a subset of those presented by Noble et al. (2003). Specifically, the present study compared pigment data collected in the 2000 sampling season and did not include samples collected in 1999 and 2001. Chl a concentrations were

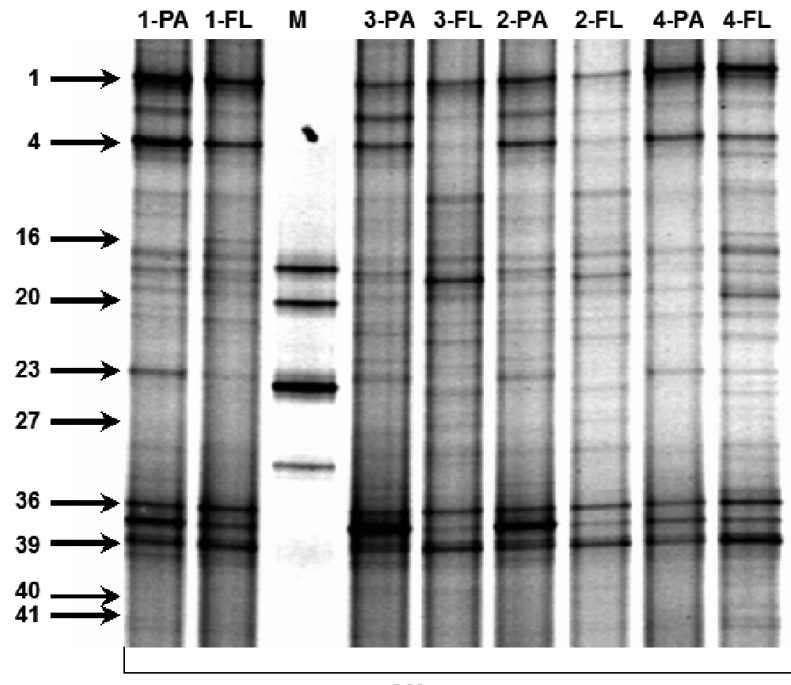

NI

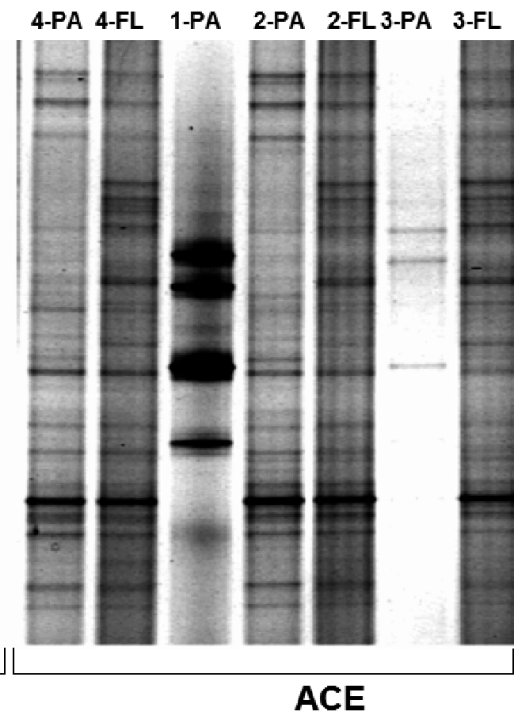

Fig. 2. DGGE image of North Inlet (NI) and Ashepoo, Combahee, and Edisto (ACE) Basin samples collected in April. Lanes are labeled according to station number; FL: free-living fraction; PA: particle-associated fraction; M: positive control markers. Relative positions of bands that were excised and sequenced are indicated by arrows 
Table 2. Salinity, chl a, dissolved organic carbon (DOC), nitrate + nitrite (NN), ammonium $\left(\mathrm{NH}_{4}\right)$, total $\mathrm{N}$ (TN), total dissolved $\mathrm{N}$ (TDN), orthophosphate $\left(\mathrm{PO}_{4}\right)$, total phosphorus (TP), and total dissolved P (TDP) from Ashepoo, Combahee, and Edisto (ACE) Basin and North Inlet (NI) samples pooled over all months samples. Values are mean $\pm \mathrm{SD}$

\begin{tabular}{|c|c|c|c|c|c|c|c|c|c|c|}
\hline Stn & $\begin{array}{l}\text { Salinity } \\
\text { (psu) }\end{array}$ & $\begin{array}{c}\mathrm{Chl} \mathrm{a} \\
\left(\mathrm{mg} \mathrm{l}^{-1}\right)\end{array}$ & $\begin{array}{c}\mathrm{DOC} \\
\left(\mathrm{mg} \mathrm{l}^{-1}\right)\end{array}$ & $\begin{array}{l}\mathrm{NN} \\
(\mu \mathrm{M})\end{array}$ & $\begin{array}{l}\mathrm{NH}_{4} \\
(\mu \mathrm{M})\end{array}$ & $\begin{array}{c}\mathrm{TN} \\
(\mu \mathrm{M})\end{array}$ & $\begin{array}{l}\text { TDN } \\
(\mu \mathrm{M})\end{array}$ & $\begin{array}{l}\mathrm{PO}_{4} \\
(\mu \mathrm{M})\end{array}$ & $\begin{array}{c}\mathrm{TP} \\
(\mu \mathrm{M})\end{array}$ & $\begin{array}{l}\text { TDP } \\
(\mu \mathrm{M})\end{array}$ \\
\hline ACE 1 & $27.57 \pm 3.7$ & $12.86 \pm 5.2$ & $5.82 \pm 1.1$ & $2.01 \pm 2.5$ & $1.43 \pm 1.4$ & $56.11 \pm 13.6$ & $39.22 \pm 12.8$ & $0.79 \pm 0.1$ & $2.48 \pm 0.5$ & $0.66 \pm 0.6$ \\
\hline 2 & $31.85 \pm 2.5$ & $8.68 \pm 2.1$ & $4.86 \pm 1.0$ & $0.87 \pm 1.0$ & $1.13 \pm 0.5$ & $51.94 \pm 10.4$ & $38.52 \pm 15.9$ & $0.71 \pm 0.2$ & $2.40 \pm 0.5$ & $0.67 \pm 0.6$ \\
\hline 3 & $33.42 \pm 1.6$ & $8.15 \pm 2.9$ & $3.78 \pm 1.6$ & $0.50 \pm 0.7$ & $0.94 \pm 0.8$ & $45.66 \pm 14.4$ & $37.39 \pm 11.1$ & $0.55 \pm 0.2$ & $1.95 \pm 0.6$ & $0.58 \pm 0.5$ \\
\hline 4 & $34.85 \pm 0.6$ & $5.87 \pm 2.3$ & $3.53 \pm 0.5$ & $0.20 \pm 0.2$ & $0.80 \pm 0.9$ & $44.92 \pm 14.3$ & $32.52 \pm 9.6$ & $0.38 \pm 0.2$ & $1.48 \pm 0.6$ & $0.33 \pm 0.5$ \\
\hline Pooled & $31 \pm 3.6$ & $8.89 \pm 4.1$ & $4.50 \pm 1.4$ & $0.90 \pm 1.5$ & $1.08 \pm 1.0$ & $49.66 \pm 13.7$ & $36.91 \pm 12.6$ & $0.61 \pm 0.2$ & $2.08 \pm 0.7$ & $0.56 \pm 0.5$ \\
\hline NI 1 & $28.28 \pm 11.8$ & $6.16 \pm 4.2$ & $17.83 \pm 22.0$ & $0.39 \pm 0.2$ & $3.32 \pm 2.7$ & $59.04 \pm 13.9$ & $46.03 \pm 22.0$ & $0.27 \pm 0.1$ & $1.33 \pm 0.8$ & $0.46 \pm 0.5$ \\
\hline 2 & $34.85 \pm 2.2$ & $8.18 \pm 3.0$ & $4.18 \pm 1.2$ & $0.17 \pm 0.1$ & $1.26 \pm 1.2$ & $46.50 \pm 26.1$ & $36.24 \pm 10.0$ & $0.22 \pm 0.1$ & $1.28 \pm 1.1$ & $0.30 \pm 0.4$ \\
\hline 3 & $35.57 \pm 0.7$ & $5.64 \pm 1.8$ & $3.61 \pm 1.1$ & $0.17 \pm 0.1$ & $1.42 \pm 0.5$ & $46.08 \pm 18.3$ & $39.83 \pm 15.9$ & $0.24 \pm 0.1$ & $1.15 \pm 0.7$ & $0.26 \pm 0.4$ \\
\hline 4 & $35.85 \pm 0.6$ & $5.78 \pm 1.3$ & $3.42 \pm 0.8$ & $0.13 \pm 0.1$ & $0.85 \pm 0.8$ & $34.39 \pm 21.3$ & $28.78 \pm 10.5$ & $0.16 \pm 0.1$ & $0.78 \pm 0.7$ & $0.13 \pm 0.3$ \\
\hline Pooled & $33.78 \pm 6.5$ & $6.44 \pm 2.9$ & $7.26 \pm 12.4$ & $0.21 \pm 0.2$ & $1.71 \pm 1.8$ & $45.88 \pm 22.1$ & $37.41 \pm 16.0$ & $0.22 \pm 0.1$ & $1.14 \pm 0.8$ & $0.29 \pm 0.4$ \\
\hline
\end{tabular}

significantly higher in ACE than in NI $(\alpha=0.05)$ and exhibited significant differences along the salinity gradients in both estuaries, with concentrations greater at stations with lower salinity (Table 2). NI samples collected in August from Stn 1 were notable exceptions to this trend, showing both the lowest chl a concentration and lowest salinity of all samples collected (data not shown). ANOVA of pigment data from both estuaries showed that most pigment concentrations were significantly higher at the landward stations than at the seaward stations for all months. However, peridinin and chl $c_{1}$ followed the opposite trend in NI samples, with higher concentrations at Stn 4 that decreased in the landward direction. Similarly, 19'-hexanoyloxyfucoxanthin (19' hex) showed a significant increase from Stn 1 to Stn 4 in both estuaries. Linear regressions of absolute pigment concentrations against salinity showed significant negative correlations for all pigments measured except peridinin, neoxanthin, 19'hex, zeaxanthin, and chl $b$.

Cluster analysis of HPLC profiles using Pearson's correlation coefficient revealed 4 major clusters (Fig. 4). Clusters A, B, and D were composed of several sub-clusters, whereas Cluster $\mathrm{C}$ was made up of a single OCU collected in September from ACE Stn 1. Cluster A1 was represented by samples from NI Stns 1, 2, and 3, with the exceptional addition of 1 sample from ACE Stn 2. Cluster A2 was mainly composed of samples from ACE Stns 1 and 2, with 2 samples from NI Stns 2 and 3. All but one of the samples in Cluster A2 was collected in April. Cluster B was divided into 3 sub- clusters at the 0.998 level: B1 represented samples from both estuaries throughout the sampling season, B2 was mostly made up of ACE samples, and B3 samples were all collected in September or October from both estuaries. Cluster D comprised exclusively samples from NI Stns 1 and 2, and could be further divided

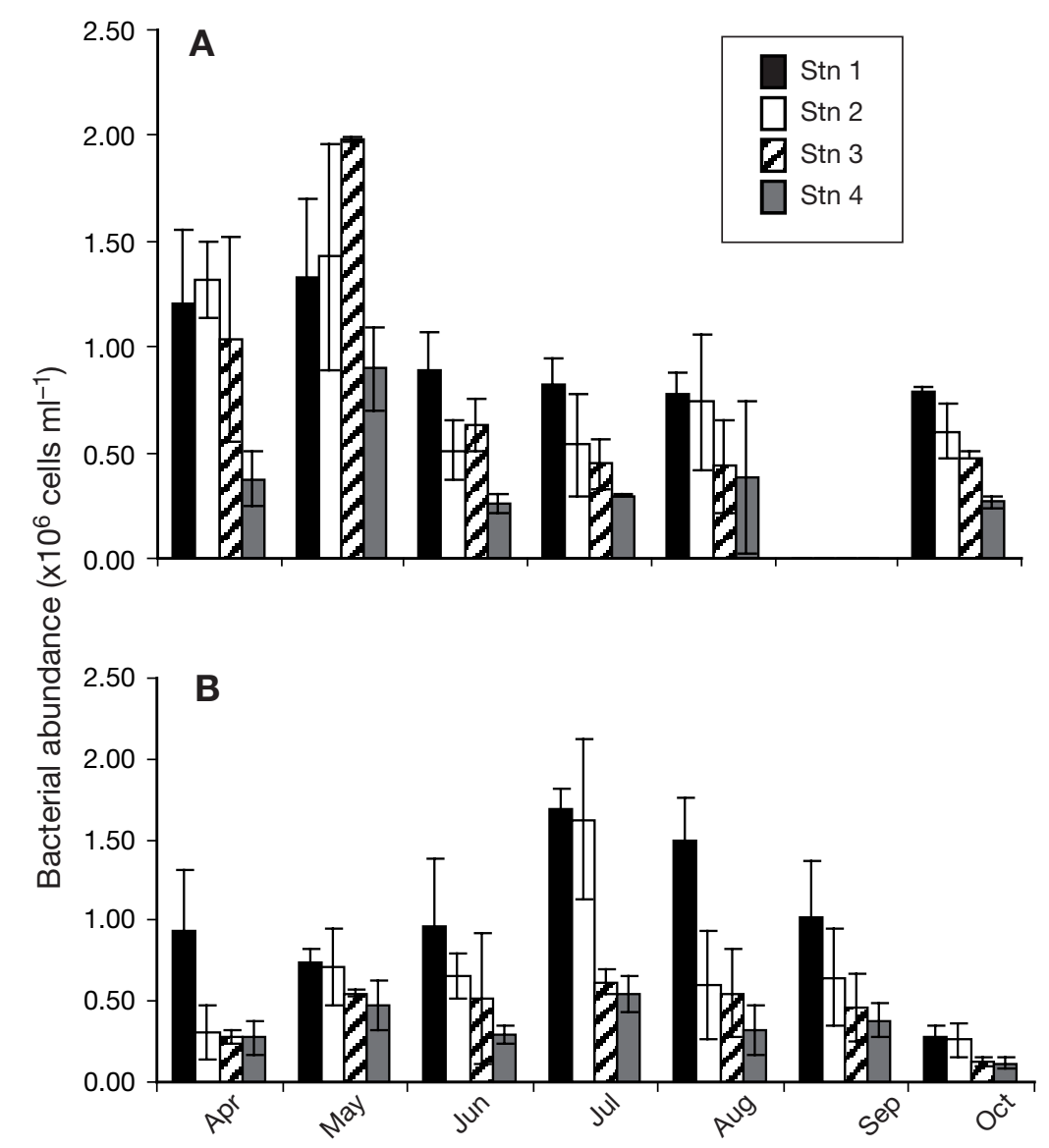

Fig. 3. Bacterial abundance from water samples collected from (A) ACE and (B) NI. Error bars $=$ SD from triplicate samples 


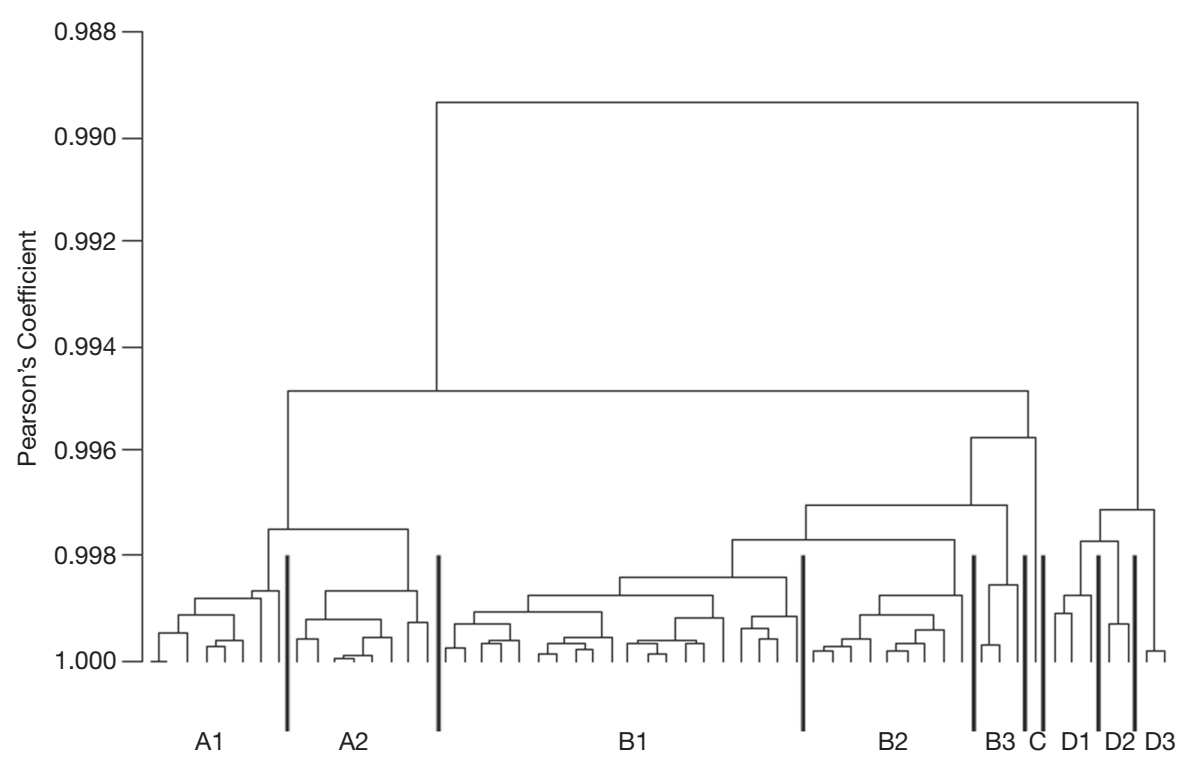

Fig. 4. HPLC profiles determined by Pearson's coefficient. Clusters at 0.996 similarity are indicated by letters, sub-clusters (similarity $>0.998$ ) by letter-number combinations

into 3 sub-clusters: D1 was composed of samples from May and June, D2 from October and May, and D3 from April.

ANOVA of normalized pigment concentrations of OCUs within clusters showed that all pigments except diadinoxanthin and alloxanthin varied significantly among clusters $(\alpha=0.05)$. Cluster B showed significantly higher concentrations of fucoxanthin, $\operatorname{chl} C$, and 19 '-hex than the other clusters. The sample that represented Cluster $C$ had significantly higher levels of peridinin than all other samples $(\alpha=0.05)$. Cluster D OCUs were characterized by higher concentrations of $19^{\prime}$ butanoyloxyfucoxanthin (19'-but), neoxanthin, prasinoxanthin, violaxanthin, lutein, chl $b$, and total carotenes than those of other clusters.

Comparisons of nutrient data across clusters showed no significant correlations between cluster groups and water chemistry except for Clusters A1 and C. Cluster A1 showed elevated DOC concentrations, and the OCU that makes up Cluster $\mathrm{C}$ was related to higher concentrations of $\mathrm{NN}$ and $\mathrm{PO}_{4}$. Both sub-clusters in Cluster A corresponded to significantly higher bacterial cell counts $(\alpha=0.05)$. Permutation tests on the similarity matrix generated in the cluster analysis showed ACE samples to be significantly different from NI samples. Furthermore, the composite photopigment patterns differed significantly from month to month in the sampling season, and exhibited significant grouping by station.

CCA comparing phytoplankton community profiles with environmental state variables gave similar patterns to those generated by permutation testing of cluster analysis, with ACE and NI samples forming distinct groups (Fig. 5). Additionally, ACE OCUs corresponded to higher concentrations of $\mathrm{PO}_{4}$ and $\mathrm{NN}$, whereas NI samples corresponded to both higher concentrations of $\mathrm{NH}_{4}$ and warmer temperatures.

\section{DGGE}

DGGE-generated community banding patterns ranged from 14 to 28 distinct bands (of 45 possible band positions) in each sample, and the most prominent 14 from each were used in the analysis. An example of the gels used in this study is shown in Fig. 2.

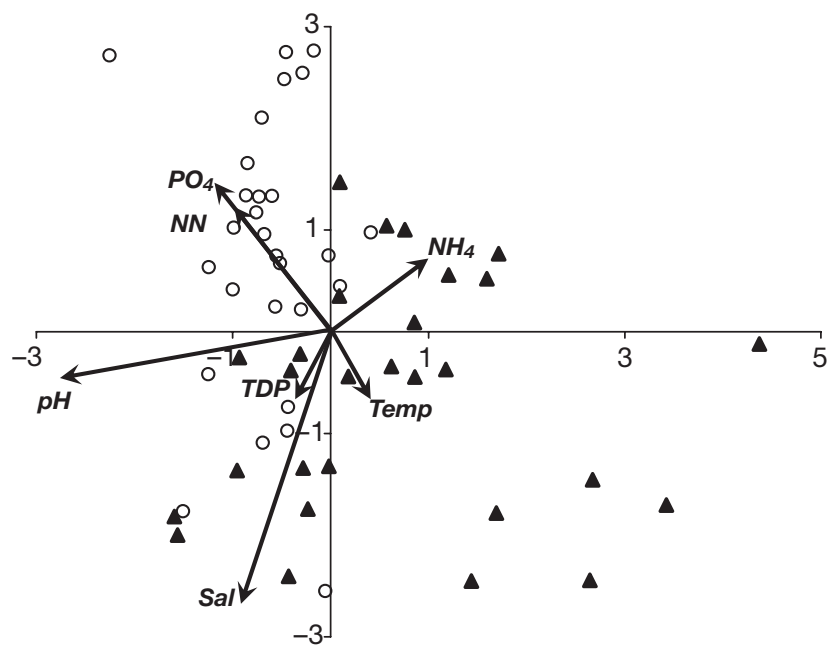

Fig. 5. Phytoplankton operational community units (OCUs) from HPLC of photopigments relative to environmental variables showing ACE (O) and NI ( $\mathbf{\Lambda})$ OCUs 
Table 3. Summary of permutation tests of UPGMA cluster patterns. $r_{\text {within }}$ and $r_{\text {between }}$ arithmetic mean over all Jaccard coefficients within and between groups, respectively; $d$ : difference between the $2 r$-values

\begin{tabular}{|lcccr|}
\hline & $r_{\text {within }}$ & $r_{\text {between }}$ & $d$ & \multicolumn{1}{c|}{$p$} \\
\hline ACE vs. NI & 0.4736 & 0.4178 & 0.0557 & $<0.0001$ \\
PA vs. FL & 0.4528 & 0.4383 & 0.0144 & 0.0003 \\
\hline
\end{tabular}

UPGMA and permutation testing of the clustering patterns pooled across all samples demonstrated OCUs to group significantly into distinct PA and FL clusters as well as significant ACE and NI clusters (Table 3). Additionally, CCA of bacterial community profiles using PA/FL fractions as a dummy environmental variable indicated that ACE OCUs tended to associate with PA characteristics, whereas NI OCUs tended to group toward the FL portion of the gradient (Fig. 6). Separate cluster analyses of PA and FL fractions further revealed OCUs to group significantly by sampling month for both fractions (Fig. 7). Station-to-station comparisons of bacterial profiles did not show any significant patterns in their distribution.

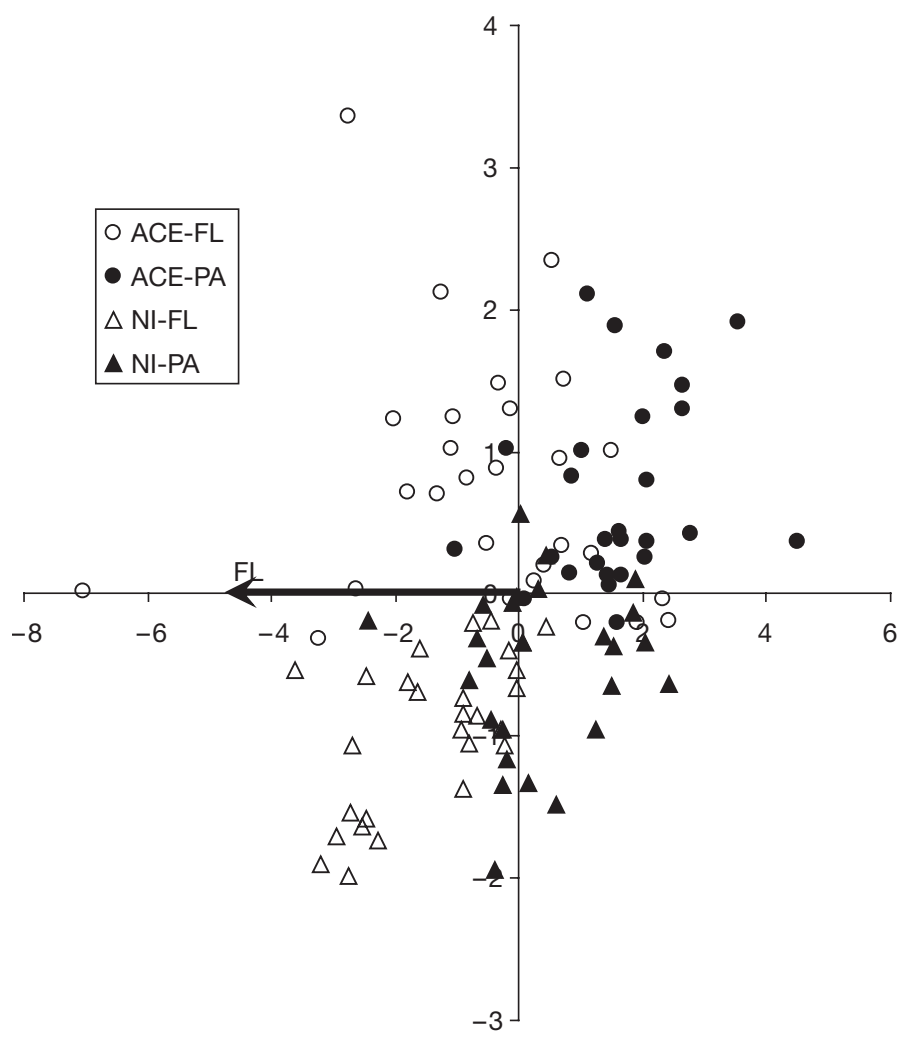

Fig. 6. Bacterial OCUs from DGGE banding patterns with particle-associated (PA)/free-living (FA) fraction as an environmental dummy variable. Gradient vector indicates the direction of increasing FL characteristics
At a Jaccard's coefficient level of 0.50, PA OCUs grouped into 10 clusters (Fig. 7A). ANOVA performed on the physical and chemical parameters of samples within clusters revealed significant differences in temperature, salinity, $\mathrm{pH}, \mathrm{DOC}, \mathrm{TP}$ and $\mathrm{NH}_{4}$ among clusters (Table 4). In pair-wise comparisons, Clusters A and F had TP concentrations that were significantly higher than those of other cluster groups. These clusters were populated almost exclusively by ACE samples collected from April to July, with a single OCU from NI in September. Cluster G OCUs exhibited concentrations of both DOC and $\mathrm{NH}_{4}$ that were significantly higher than in all other clusters. Inversely, this cluster exhibited $\mathrm{pH}$ and salinity levels that were significantly lower than in all the other clusters except Cluster J. Cluster G was made up of a single OCU from NI Stn 1 water samples from August, which were collected following a rain event, and Cluster $\mathrm{J}$ was composed of a single OCU representing the May sample from NI Stn 4. Pairwise comparisons further revealed that the lowest concentrations of DOC were from Cluster E, which was composed of 2 OCUs collected from ACE Stns 3 and 4 in September. Although the global p-value for ANOVA of temperature effects showed the differences to be significant, the only significant pair-wise contrast was that between Cluster C (May and June samples) and Cluster I (April samples) OCUs, with Cluster C exhibiting higher temperatures.

FL samples grouped into 11 clusters at Jaccard's coefficient level of 0.50 (Fig. 7B). ANOVA of the physicochemical factors of these OCUs showed temperature, salinity, $\mathrm{NH}_{4}, \mathrm{NN}, \mathrm{TP}$, and $\mathrm{PO}_{4}$ to differ significantly among clusters (Table 5). Pair-wise comparisons showed that Clusters D and $\mathrm{H}$ exhibited higher salinities than other clusters. Clusters D and H were both composed primarily of NI samples, with Cluster D largely comprising samples collected from June and July, and Cluster $\mathrm{H}$ entirely comprising samples collected in May. Cluster D also exhibited higher temperatures than all other clusters except Cluster I, which was composed of OCUs from ACE samples collected in June. $\mathrm{NH}_{4}$ concentrations were highest in Cluster $\mathrm{E}$ (NI, samples collected from September and October) and significantly lower in Clusters H, I, and J. Cluster J OCUs exclusively comprised ACE samples collected in June, August, and September. Pair-wise comparisons also showed Cluster $\mathrm{J}$ to have the highest NN concentrations of all the clusters. Concentrations of TP and $\mathrm{PO}_{4}$ were highest in Clusters B and $\mathrm{J}$, respectively. Both of these clusters were populated entirely by ACE OCUs: Cluster B was composed of samples collected in May, and Cluster J OCUs of samples collected from June to September.

ANOVA of photopigment concentrations (normalized to $\mathrm{chl}$ a) from the bacterial community clusters 

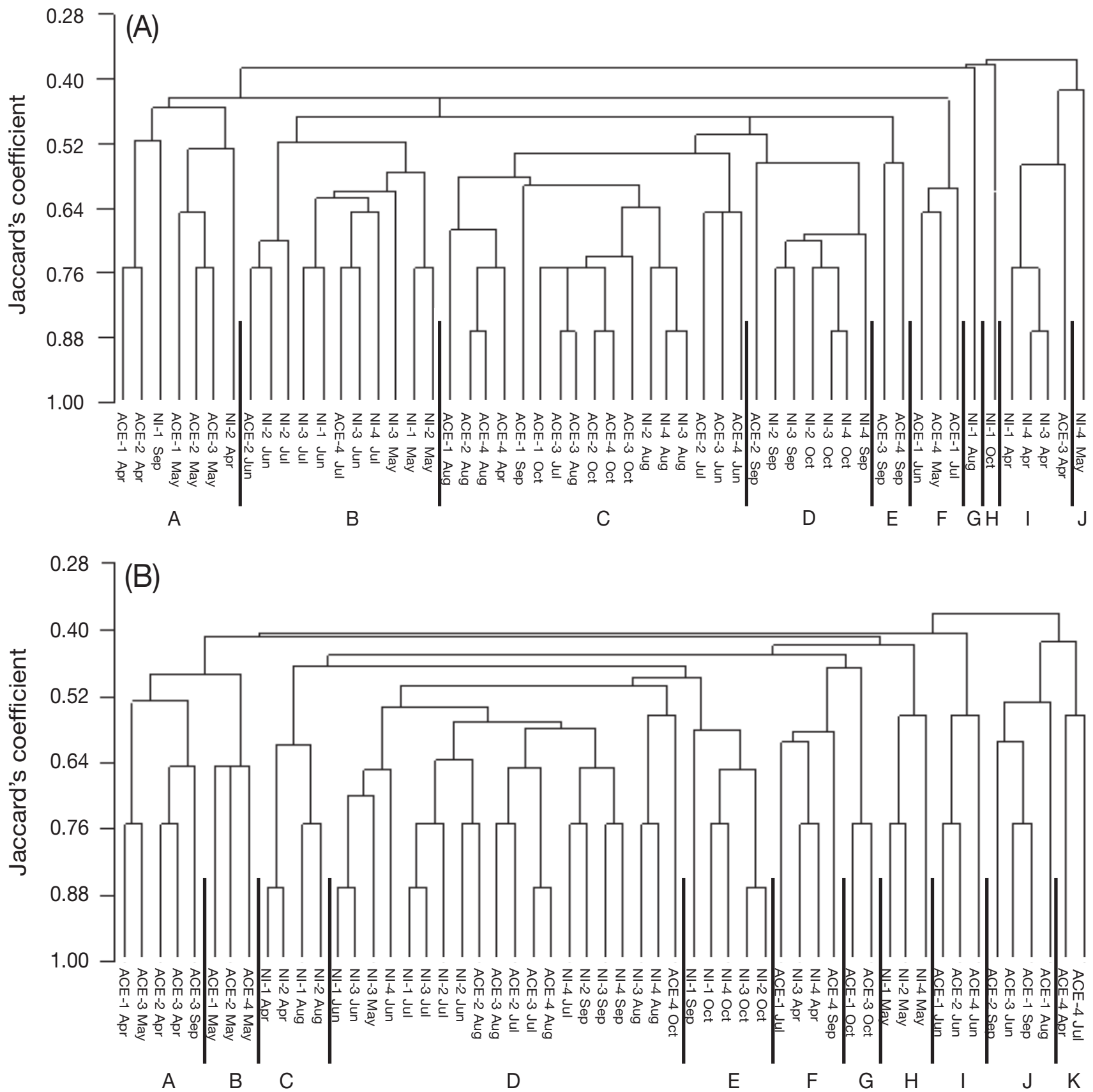

Fig. 7. Clustering of (A) PA and (B) FL samples from both estuaries for all months. OCUs are labeled according to estuary (ACE or NI), station number, and month. Clusters at 0.50 similarity are indicated by letters

identified by UPGMA revealed significant differences in photopigments for both PA and FL community profiles. ANOVA of photopigments from PA community clusters showed significant differences in chl $b$, chl $c_{1}$, fucoxanthin, alloxanthin, diadinoxanthin, and diatoxanthin at the $0.05 \alpha$-level (Table 4). Pair-wise comparisons of relative chl $b$ concentrations indicated that only Clusters B (ACE May and NI April) and I (ACE and NI April) differed significantly from one another after Tukey corrections for multiple comparisons. Comparisons of $\operatorname{chl} C_{1}$ values showed that the 2 OCUs from Cluster E (ACE September samples) had the highest relative concentrations of this pigment. Although globally significant ( $\alpha=0.05$ ), the differences in both fucoxanthin and alloxanthin concentrations among clusters were not significant in any pair-wise comparisons. Both diadinoxanthin and diatoxanthin were highest in the single NI October OCU in Cluster $\mathrm{H}$, and lowest in OCUs from Clusters B and I. 


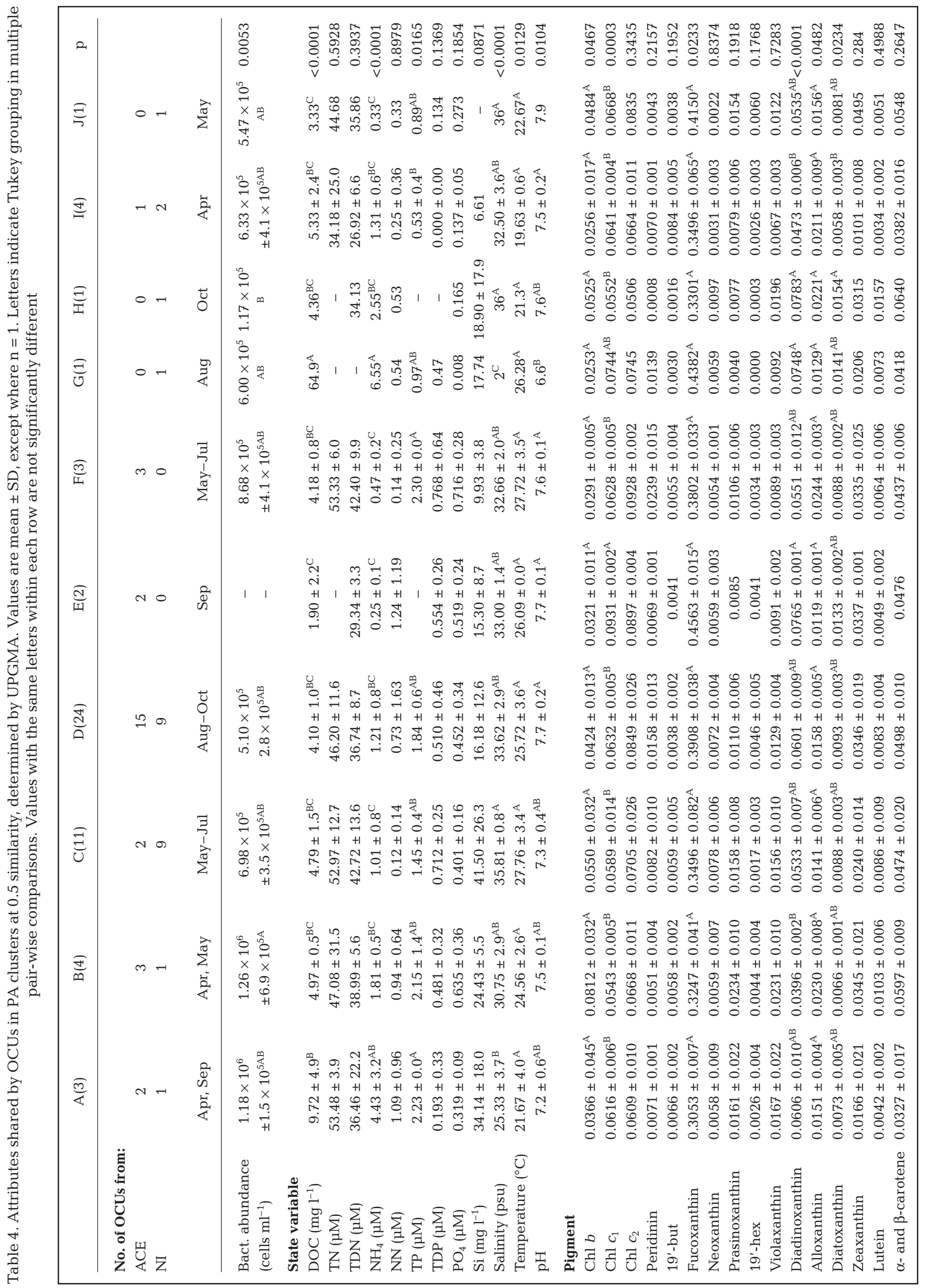




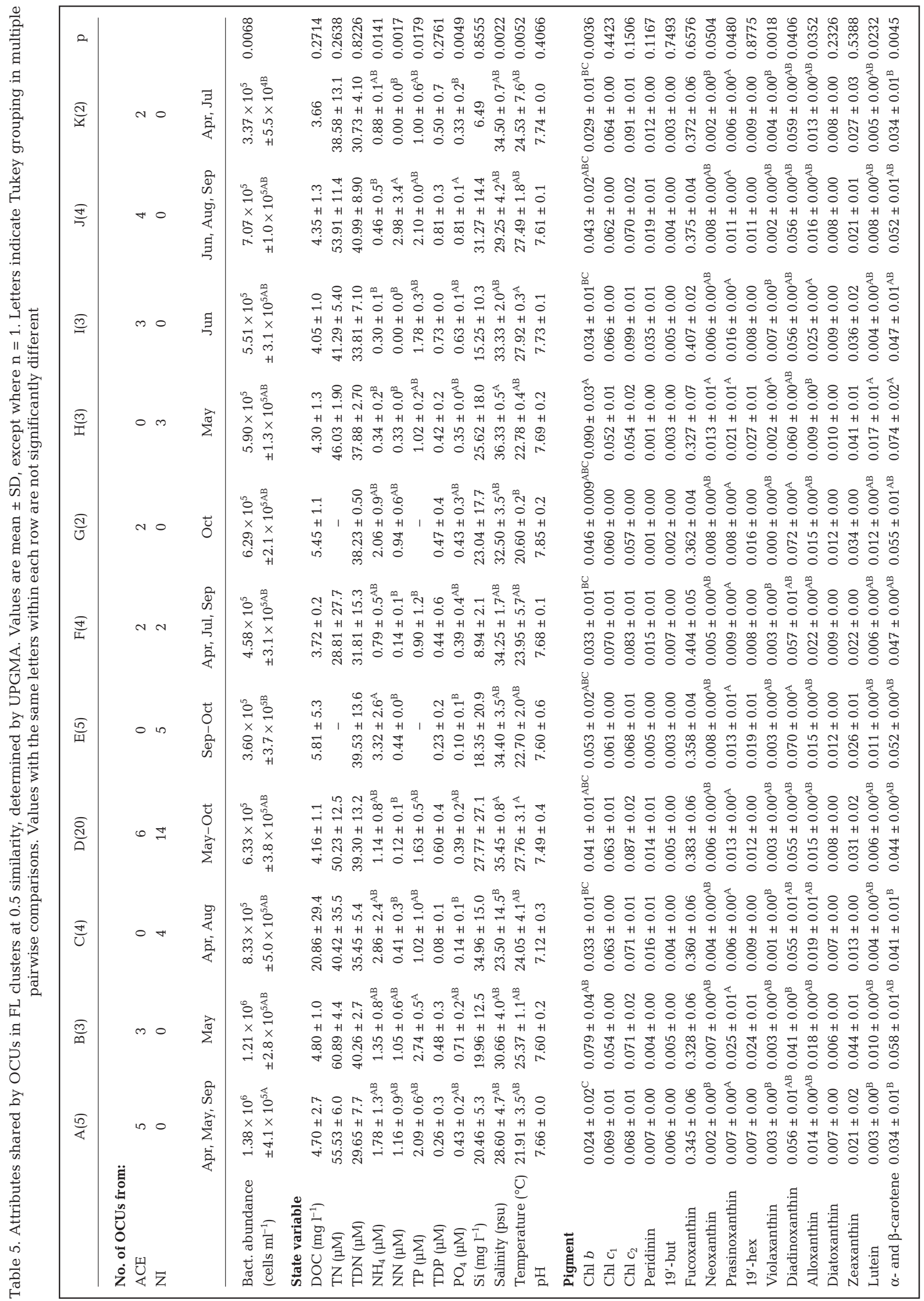


ANOVA of relative photopigment concentrations classified by FL bacterial clusters revealed significant differences in chl $b$, neoxanthin, prasinoxanthin, violaxanthin, diadinoxanthin, alloxanthin, lutein, and $\alpha$ and $\beta$-carotenes (Table 5). In pair-wise comparisons, Cluster H (NI May) exhibited the highest concentrations of chl $b$, neoxanthin, violaxanthin, lutein, and $\alpha$ and $\beta$-carotenes. This cluster also corresponded to the lowest concentrations of alloxanthin. Relative concentrations of diadinoxanthin were highest in Clusters G and E, which are composed of OCUs from NI and ACE from September and October. Significantly lower concentrations of diadinoxanthin were found in OCUs from Cluster B (ACE May). Normalized concentrations of prasinoxanthin were significant globally, but no significant pair-wise differences were detected.

Sequence data from excised bands representing 10 of the 45 potential band positions confirmed the positioning determined by image analysis among DGGE gels. Furthermore, comparisons of these sequences to known sequences in GenBank indicated that the bands were indeed representative of marine or estuarine organisms. Specifically, the bands at Positions 1 and 4 were each composed of a single sequence with $100 \%$ homology to several uncultured marine Bacteroidetes organisms and were found in 85 and 92 OCUs, respectively. Three organisms were represented in Band 16; Acinetobacter sp. 11, an uncultured salt marsh Ectothiorhodospiraceae sp., and an uncultured $\alpha$-Proteobacterium. This band was scored in 97 of the 109 OCUs. It should be noted that because DGGE separates fragments based on melting characteristics rather than strictly by sequence, it is quite common to find bands that are composed of multiple sequences. For this study we assumed that bands at the same position between gels were identical in composition even though they were not all sequenced. Although this limited our ability to perform detailed analyses of the actual compositions of the communities, it provided for conservative measure of pattern differences and greatly reduced any Type II error in our analysis. Band 20 was present in 66 of the community profiles and was made up of 2 distinct sequences, one with 100\% homology to an uncultured marine Bacteroidetes organism and the other matching the V3 16S rRNA gene sequence of Marinobacter arcticus. Band 23 included sequences with $100 \%$ similarity to uncultured marine $\gamma$ - and $\beta$-Proteobacteria. Eighty OCUs contained bands at Position 27 that showed 100\% homology to uncultured Bacteroidetes and Roseobacter 16S r RNA gene sequences. Band 36, which was seen in 72 of the bacterial community profiles, was composed of a single sequence that matched the $16 \mathrm{~S}$ rRNA gene sequence from a Sphingomonas sp. organism. The most common bands were those at Positions
39 and 40, which were observed in 105 and 104 OCUs, respectively. Band 39 contained sequences homologous to an uncultured $\gamma$-Proteobacterium, an uncultured $\beta$-Proteobacterium, and an uncultured Bacteroidetes organism. Band 40 was composed of a single sequence that matched 16S rRNA from a different uncultured $\alpha$-Proteobacterium. Band 41 was also composed of a single $\alpha$-Proteobacterium sequence and was observed in 47 of the 109 OCUs. Unfortunately, the sequences obtained from gel bands predominantly matched 16S rRNA from uncultured or unidentified organisms, and because they are relatively short fragments, each sequence has $100 \%$ similarity to several taxa from available DNA sequence databases. As a result, clear identification of the specific taxa involved is not possible from our data; however, results from BLAST searches do show 100\% homology of the most frequently occurring bands to uncultured or unidentified organisms collected from marine or estuarine environments.

\section{DISCUSSION}

Water chemistry, photopigment distribution, and bacterial community composition all demonstrated clear differences between the ACE Basin and NI estuaries. The differences in nutrient concentrations between ACE and NI samples correlated closely with salinity differences between the systems, indicating that the larger drainage basin and higher riverine input in ACE affect the overall chemistry of the estuary; in contrast, the NI is more tidally dominated, reflecting its relatively small drainage. The influence of freshwater, riverine inflow on overall nutrient chemistry may have been further indicated by the increase in TDP in the seaward direction as observed for ACE samples. Total suspended solids in ACE were shown to be significantly higher than in NI (Noble et al. 2003), and, as reported by Gardolinski et al. (2004), bound phosphorus tends to be released into the water column from river-borne particles as salinity increases. Additional evidence for the influence of freshwater input on total water chemistry was apparent in NI Stn 1 samples from August, which were collected only a few hours after a rain event. Freshwater loading into the systems was indicated by lower salinity and higher concentrations of $\mathrm{NH}_{4}$ and DOC than samples previously, or subsequently, collected from that station; however, the TDP and $\mathrm{PO}_{4}$ concentrations on that date were significantly lower than those of all other samples collected at that site, whereas TP measurements were not. Therefore, although the total amount of $\mathrm{P}$ in the water at this station remained unchanged, it was almost entirely associated with particles. These deviations in water 
chemistry were likely due to inflow of freshwater that had been enriched with $\mathrm{DOC}, \mathrm{NH}_{4}$, and P-rich particulate material from the terrestrial component of the estuary.

Within each estuary the nutrient patterns typically followed the salinity gradient, with lower nutrient concentrations generally found in the seaward direction, presumably due to dilution in seawater. These trends were more apparent in ACE than in NI, and are similar to trends in nutrient chemistry found in other estuaries on the eastern seaboard of North America that are characterized by large river inputs and relatively little oceanic influence (Christian et al. 1991, Bouvier \& del Giorgio 2002). In contrast, NI nutrient patterns showed decreasing concentrations of $\mathrm{NN}$ and $\mathrm{PO}_{4}$, similar to results obtained by Verity (2002) in a study of hydrology and nutrient dynamics within a tidally dominated salt marsh estuary on the Georgia coast.

Results of phytoplankton community analysis largely agree with those of Noble et al. (2003), with greater phototrophic biomass in the ACE Basin, consistent with the influence of riverine input on increasing nutrient availability and consequent stimulation of phytoplankton production. The findings of Noble et al. (2003) further indicated spatial and temporal changes, with higher concentrations of pigments indicative of diatoms, dinoflagellates, haptophytes, and cryptophytes in ACE samples and higher levels of pigments associated with chlorophytes, prasinophytes and/or cyanobacteria in NI samples.

For most of the pigments measured, absolute concentrations were negatively correlated with salinity but relative concentrations were not, indicating that although the salinity gradient and corresponding nutrient gradients had an effect on the overall size of the population, under most conditions they had little direct effect on the structure of the community. However, comparisons of water chemistry with photopigments do suggest that the composition of the phytoplankton community may have changed in response to sufficiently large shifts in nutrient concentration. Specifically, samples from ACE Stn 1 in September showed a 2-fold increase in NN concentration relative to other samples from that estuary. This corresponded to a greater than 2-fold increase in both the absolute and relative concentrations of peridinin, a dinoflagellate pigment, indicating an increase in dinoflagellate biomass and an increase in their relative abundance within the phytoplankton community, and may be indicative of a small-scale bloom event.

As with the pigment profiles, DGGE banding patterns showed some overlap among samples, yet still showed significant differences based on cluster analysis. Cluster analysis of all samples as a single data set revealed significant grouping of community profiles into $\mathrm{ACE}$ and NI clusters, demonstrating that each estuary supported a measurably different bacterial community. Additionally, both estuaries exhibited significant differences in FL and PA bacterial communities. The absence of systematic variation in station-tostation comparisons within the estuaries suggests that, although there may be differences in bacterial community composition along the chemical gradients, these differences are much smaller than the variation between estuaries and the differences between FL and PA fractions of the bacterioplankton.

Comparisons made among ecological properties of the clusters defined in UPGMA demonstrated compositional differences in bacterial communities that corresponded to differences in several state variables. Although differences in community patterns did not strictly follow the salinity gradients observed within the 2 estuaries, there was a clear effect of salinity on the composition in general, mostly due to salinity differences between ACE and NI. Other research has shown measurable changes along salinity gradients in other estuaries as well as differences between estuaries (Schultz \& Ducklow 2000, Bouvier \& del Giorgio 2002, del Giorgio \& Bouvier 2002). Our work is not necessarily in disagreement with such findings. Rather, we suggest that the narrow range of bacterial groups observed in our gels did not allow for the scale necessary to reveal broad differences in community structures. For example, although a clear shift in community composition from $\beta$-Proteobacteria in the freshwater regions of the Choptank River (a sub-estuary of Chesapeake Bay) to $\alpha$-Proteobacteria further down the estuary was shown using fluorescent in situ hybridization with group-specific probes (Bouvier \& del Giorgio 2002, del Giorgio \& Bouvier 2002), the gradient we selected predominantly resolved unidentified members of the $\alpha$-subclass of Protebacteria and unidentified members of the class Bacteroidetes, and only detected a single unidentified $\beta$-proteobacterial sequence.

Significant differences in the composition of both PA and FL assemblages were associated with differences in phosphorus and nitrogen concentrations; however, the 2 fractions were affected by different species of those elements. FL community clusters showed significant differences in $\mathrm{NH}_{4}$ and $\mathrm{NN}$ concentrations, whereas PA clusters exhibited differences only in levels of $\mathrm{NH}_{4}$. Clusters from both fractions also showed significant differences in the amount of TP present in the water column; however, only the FL fraction exhibited significant differences in the concentration of $\mathrm{PO}_{4}$ among clusters. This is consistent with the concept that PA organisms use particles as refugia and as sources for nutrition and are thereby subject to microzone nutrient chemistry, whereas FL organisms are more 
directly influenced by bulk water chemistry (Cho \& Azam 1988). Additionally, $\mathrm{NN}$ and $\mathrm{PO}_{4}$ tend to be more bioreactive than $\mathrm{NH}_{4}$ and particulate or organic phosphorus, and are likely to be rapidly scavenged directly from the water column, thus affecting FL cells more rapidly than PA cells. PA clusters also exhibited significant differences in DOC concentrations among cluster groups; however, the cluster that exhibited the highest concentration was composed of OCUs from samples collected following a rain event. This cluster had DOC concentrations more than 6 times greater than those of other clusters and salinity that was uncharacteristic for this site, indicating that this sample represented allochthonous input of water, nutrients, and likely, particulates, thus physically introducing a new PA community rather than causing a compositional shift in the preexisting PA assemblage.

Comparisons of photopigment concentrations among bacterial profile clusters demonstrated clear compositional associations between PA and FL communities. Clusters identified in PA OCUs demonstrated significant differences in concentrations of pigments attributable to diatoms, some dinoflagellates, haptophytes and cryptophytes, with the lowest concentrations of these pigments occurring in association with clusters composed of OCUs from April and May. Relatively higher levels of these pigments are associated with OCUs from September and October, suggesting a seasonal component that is consistent within both phytoplankton and PA bacterial communities.

A recent study by Rooney-Varga et al. (2005) showed a similar association of the PA bacterial assemblage to phytoplankton community composition in the Bay of Fundy, particularly with respect to diatom abundance within the community. Interestingly, these researchers classified phytoplankton by morphology and 18S rRNA genes (Savin et al. 2004), characterized bacterial communities using a 520 bp 16S rRNA gene fragment, and employed a direct gradient multivariate statistical test, and still detected strikingly similar patterns of association between the phytoplankton and bacterial communities. Similarly, Pinhassi et al. (2003) found clear differences in the relative concentrations of prymnesiophyte and diatom marker pigments that corresponded to measured differences in bacterial community compositions in the frontal zone between the North and Baltic Seas; however, their study did not separate the FL and PA communities. From these few studies, it seems that these associations are robust across large geographic scales and, because ecological states vary widely among the study sites, are likely indicative of specific interactions between organisms rather than simultaneous response to state variables.

In contrast, FL bacterial community clusters showed significant differences in pigments that correspond almost entirely to chlorophytes, prasinophytes, and cyanobacteria. These organisms tend to dominate in oligotrophic coastal systems that rely on remineralization through microbial processes for much of the community nutrient demand.

The present study's findings extend those of Noble et al. (2003) in comparisons of 2 southeastern salt marsh estuaries minimally affected by anthropogenic activities, but differing in watershed area and therefore in allochthonous nutrient and sediment loading. The fact that the estuary with the higher watershed area (ACE Basin) was characterized by relatively high contributions of PA bacteria and diatoms is understandable because of their common associations with suspended sediments (Millie et al. 2002). A greater dependency of ACE microbial communities with new (allochthonous) nitrogen sources is suggested by the predominant contribution of diatom and dinoflagellate pigments when normalized to chl a. An example of the positive association of diatoms with nitrate is documented in the spring bloom formation in temperate estuaries, while a close relationship between peridinin and nitrate was demonstrated in this study. One implication from these findings is that the relative contribution of diatoms (and possibly some types of dinoflagellates) to phytoplankton biomass, and of PA bacterial biomass to total bacterial biomass, may correlate positively with watershed area.

NI, the estuary with the smaller watershed and lower nutrient and sediment loading, was characterized by greater relative contributions of FL bacteria and pigments indicative of chlorophytes, prasinophytes, and/or cyanobacteria to microbial community composition. Noble et al. (2003) discussed inter-estuary differences in the seasonal timing of the phytoplankton bloom, and suggested that these differences reflected a prototypical spring phytoplankton bloom driven by allochthonous nutrient loading in the ACE Basin versus a summer bloom in NI. This was characterized by microbial loop dynamics that included an important influence of microzooplankton grazing and regenerated nutrients, and a close coupling between phytoflagellates and bacteria (Lewitus et al. 1998). Of the potential phytoplankton groups implicated by the pigment patterns, prasinophytes and cyanobacteria are most consistent with results from previous studies in NI (Lewitus et al. 1998, 2005, Kulkarni et al. 2005), and typify phytoplankton associated with microbial loop communities. The inference that such microbial loop communities would involve nutrient and energy cycling within microaggregates (Caron et al. 1988) is rational for a predominant involvement of FL bacteria rather than macroaggregate-associated PA bacteria.

In summary, pronounced differences in bacteria and phytoplankton community structure were found in 2 
southeastern estuaries that could ultimately be attributed to differences in the size of their watershed and, consequently, the relative influences of allochthonous and autochthonous regulation. Both estuaries are minimally affected by anthropogenic activities, and the ACE Basin may therefore be considered to represent a natural salt marsh in a more advanced state of eutrophication than NI. In this sense, one can speculate that the affects of urbanized development (increased impervious surfaces, stream channelization, non-point source nutrient loading etc.) on the NI ecosystem may promote shifts in microbial community structure and function toward those found in the ACE Basin. These include higher primary and secondary productivity, a change from a nanoflagellate-dominated phytoplankton assemblage to one dominated by diatoms, and a trend toward an increased importance of macroaggregate- over microaggregate-associated trophic dynamics.

Acknowledgements. We acknowledge the financial support of EPA through the CISNET Landscape-scale Ecological Monitoring program. We thank P. A. Noble, R. Tymowski, and J. Gettys for their valuable contributions to sample collection and analysis.

\section{LITERATURE CITED}

Bidle KD, Fletcher M (1995) Comparison of free-living and particle-associated bacterial commmunities in the Chesapeake Bay by stable low-molecular-weight RNA analysis. Appl Environ Microbiol 61:944-952

Boon N, De Windt W, Verstraete W, Top EM (2002) Evaluation of nested PCR-DGGE (denaturing gradient gel electrophoresis) with group-specific 16S rRNA primers for the analysis of bacterial communities from different wastewater treatment plants. FEMS Microbiol Ecol 39:101-112

Bordalo AA, Vieira MEC (2005) Spatial variability of phytoplankton, bacteria and viruses in the mesotidal salt wedge Douro Estuary (Portugal). Estuar Coast Shelf Sci 63: 143-154

Bouvier TC, del Giorgio PA (2002) Compositional changes in free-living bacterial communities along a salinity gradient in two temperate estuaries. Limnol Oceanogr 47:453-470

Caron DA, Goldman JC, Dennett MR (1988) Experimental demonstration of the roles of bacteria and bacterivorous protozoa in plankton nutrient cycles. Hydrobiologia 159: $27-40$

Cho BC, Azam F (1988) Major role of bacteria in biogeochemical fluxes in the oceans interior. Nature 332:441-443

Christian RR, Boyer JN, Stanley DW (1991) Multiyear distribution patterns of nutrients within the Neuse River Estuary, North Carolina. Mar Ecol Prog Ser 71:259-274

Dame R, Alber M, Allen D, Mallin M and 8 others (2000) Estuaries of the south Atlantic coast of North America: their geographical signatures. Estuaries 23:793-819

del Giorgio PA, Bouvier TC (2002) Linking the physiologic and phylogenetic successions in free-living bacterial communities along an estuarine salinity gradient. Limnol Oceanogr 47:471-486
Fandino LB, Riemann L, Steward GF, Long RA, Azam F (2001) Variations in bacterial community structure during a dinoflagellate bloom analyzed by DGGE and 16S rDNA sequencing. Aquat Microb Ecol 23:119-130

Fernandez A, Huang SY, Seston S, Xing J, Hickey R, Criddle C, Tiedje J (1999) How stable is stable? Function versus community composition. Appl Environ Microbiol 65:3697-3704

Ferris MJ, Muyzer G, Ward DM (1996) Denaturing gradient gel electrophoresis profiles of 16S rRNA-defined populations inhabiting a hot spring microbial mat community. Appl Environ Microbiol 62:340-346

Gardolinski P, Worsfold PJ, McKelvie ID (2004) Seawater induced release and transformation of orgganic and inorganic phosphorus from river sediments. Water Res 38:688-692

Hansen MC, Tolker-Nielsen T, Givskov M, Molin S (1998) Biased 16S rDNA PCR amplification caused by interference from DNA flanking the template region. FEMS Microbiol Ecol 26:141-149

Higgins HW, Mackey DJ (2000) Algal class abundances, estimated from chlorophyll and carotenoid pigments, in the western Equatorial Pacific under El Niño and non-El Niño conditions. Deep-Sea Res I 47:1461-1483

Hollibaugh JT, Wong PS, Murrell MC (2000) Similarity of particle-associated and free-living bacterial communities in northern San Francisco Bay, California. Aquat Microb Ecol 21:103-114

Kanagawa T (2003) Bias and artifacts in multitemplate polymerase chain reactions (PCR). J Biosci Bioeng 96:317-323

Kirchman DL, Suzuki Y, Garside C, Ducklow HW (1991) High turnover rates of dissolved organic-carbon during a spring phytoplankton bloom. Nature 352:612-614

Kirchman DL, Dittel AI, Findlay SEG, Fischer D (2004) Changes in bacterial activity and community structure in response to dissolved organic matter in the Hudson River, New York. Aquat Microb Ecol 35:243-257

Kropf S, Heuer H, Gruning M, Smalla K (2004) Significance test for comparing complex microbial community fingerprints using pairwise similarity measures. J Microbiol Methods 57:1187-195

Kulkarni NR, White DL, Lewitus AJ, Tymowski RG, Yoch DC (2005) Dimethylsulfoniopropionate in a salt marsh estuary: correlation to tidal cycle and phytoplankton assemblage composition. Mar Ecol Prog Ser 289:13-25

Lagus A, Suomela J, Weithoff G, Heikkila K, Helminen $H_{\text {, }}$ Sipura J (2004) Species-specific differences in phytoplankton responses to $\mathrm{N}$ and $\mathrm{P}$ enrichments and the $\mathrm{N}$ : $\mathrm{P}$ ratio in the Archipelago Sea, northern Baltic Sea. J Plankton Res 26:779-798

LaPara TM, Nakatsu CH, Pantea LM, Alleman JE (2002) Stability of the bacterial communities supported by a sevenstage biological process treating pharmaceutical wastewater as revealed by PCR-DGGE. Water Res 36:638-646

Lassen MF, Bramm ME, Richardson K, Yusoff F, Shariff M (2004) Phytoplankton community composition and size distribution in the Langat River Estuary, Malaysia. Estuaries 27:716-727

Lewitus AJ, Koepfler ET, Morris JT (1998) Seasonal variation in the regulation of phytoplankton by nitrogen and grazing in a salt-marsh estuary. Limnol Oceanogr 43:636-646

Lewitus AJ, White DL, Tymowski RG, Geesey ME, Hymel SN, Noble PA (2005) Adapting the CHEMTAX method for assessing phytoplankton taxonomic composition in southeastern US estuaries. Estuaries 28:160-172

Lind OT, Barcena E (2003) Response of riverine and transition zone bacterioplankton communities to a pulsed river inflow. Hydrobiologia 504:79-85 
Lovell CR, Steward CC, Phillips T (1999) Activity of marine sediment bacterial communities exposed to 4-bromophenol, a polychaete secondary metabolite. Mar Ecol Prog Ser 179:241-246

Lovell CR, Bagwell CE, Czako M, Marton L, Piceno YM, Ringelberg DB (2001) Stability of a rhizosphere microbial community exposed to natural and manipulated environmental variability. FEMS Microbiol Ecol 38:69-76

Lueders T, Friedrich MW (2003) Evaluation of PCR amplification bias by terminal restriction fragment length polymorphism analysis of small-subunit rRNA and mcrA genes by using defined template mixtures of methanogenic pure cultures and soil DNA extracts. Appl Environ Microbiol 69:320-326

Millie DF, Fahnenstiel GL, Carrick HJ, Lohrenz SE, Schofield OME (2002) Phytoplankton pigments in coastal Lake Michigan: distributions during the spring isothermal period and relation with episodic sediment resuspension. J Phycol 38:639-648

Morris J (2000) Effects of sea-level anomalies on estuarine process. In: Hobbie JE (ed) Estuarine science: a synthetic approach to research and practice. Island Press, Washington, DC, p 107-127

Muyzer G, Dewaal EC, Uitterlinden AG (1993) Profiling of complex microbial populations by denaturing gradient gel-electrophoresis analysis of polymerase chain reactionamplified genes-coding for $16 \mathrm{~s}$ ribosomal-RNA. Appl Environ Microbiol 59:695-700

Noble PA, Bidle KD, Fletcher M (1997) Natural microbial community compositions compared by a back-propagating neural network and cluster analysis of 5S rRNA. Appl Environ Microbiol 63:1762-1770

Noble PA, Tymowski RG, Fletcher M, Morris JT, Lewitus AJ (2003) Contrasting patterns of phytoplankton community pigment composition in two salt marsh estuaries in southeastern United States. Appl Environ Microbiol 69: 4129-4143

Paerl HW, Valdes LM, Pinckney JL, Piehler MF, Dyble J, Moisander PH (2003) Phytoplankton photopigments as indicators of estuarine and coastal eutrophication. Bioscience 53:953-964

Piceno YM, Lovell CR (2000) Stability in natural bacterial communities: I. Nutrient addition effects on rhizosphere diazotroph assemblage composition. Microb Ecol 39:32-40

Pinckney JL, Richardson TL, Millie DF, Paerl HW (2001) Application of photopigment biomarkers for quantifying microalgal community composition and in situ growth rates. Org Geochem 32:585-595

Pinhassi J, Winding A, Binnerup SJ, Zweifel UL, Riemann B, Hagström Å (2003) Spatial variability in bacterioplankton community composition at the Skagerrak-Kattegat Front. Mar Ecol Prog Ser 255:1-13

Pinhassi J, Sala MM, Havskum H, Peters F, Guadayol O, Malits A, Marrase CL (2004) Changes in bacterioplankton composition under different phytoplankton regimens. Appl Environ Microbiol 70:6753-6766

Editorial responsibility: William Li,

Dartmouth, Nova Scotia, Canada
Riemann L, Winding A (2001) Community dynamics of freeliving and particle-associated bacterial assemblages during a freshwater phytoplankton bloom. Microb Ecol 42: $274-285$

Rodriguez F, Varela M, Zapata M (2002) Phytoplankton assemblages in the Gerlache and Bransfield Straits (Antarctic Peninsula) determined by light microscopy and CHEMTAX analysis of HPLC pigment data. Deep-Sea Res II 49:723-747

Rooney-Varga JN, Giewat MW, Savin MC, Sood S, LeGresley M, Martin JL (2005) Links between phytoplankton and bacterial community dynamics in a coastal marine environment. Microb Ecol 49:163-175

Savin MC, Martin JL, LeGresley M, Giewat M, Rooney-Varga $\mathrm{J}$ (2004) Plankton diversity in the Bay of Fundy as measured by morphological and molecular methods. Microb Ecol 48:51-65

Schultz GE, Ducklow H (2000) Changes in bacterioplankton metabolic capabilities along a salinity gradient in the York River estuary, Virginia, USA. Aquat Microb Ecol 22:163-174

Seitzinger SP, Sanders RW (1999) Atmospheric inputs of dissolved organic nitrogen stimulate estuarine bacteria and phytoplankton. Limnol Oceanogr 44:721-730

Sekiguchi H, Koshikawa H, Hiroki M, Murakami S and 5 others (2002) Bacterial distribution and phylogenetic diversity in the Changjiang estuary before the construction of the Three Gorges Dam. Microb Ecol 43:82-91

Selje N, Simon M (2003) Composition and dynamics of particle-associated and free-living bacterial communities in the Weser Estuary, Germany. Aquat Microb Ecol 30:221-237

Smith EM, Kemp WM (2003) Planktonic and bacterial respiration along an estuarine gradient: responses to carbon and nutrient enrichment. Aquat Microb Ecol 30:251-261

Stephen JR, Kowalchuk GA, Bruns MAV, McCaig AE, Phillips CJ, Embley TM, Prosser JI (1998) Analysis of betasubgroup proteobacterial ammonia oxidizer populations in soil by denaturing gradient gel electrophoresis analysis and hierarchical phylogenetic probing. Appl Environ Microbiol 64:2958-2965

Trimmer M, Purdy KJ, Nedwell DB (1997) Process measurement and phylogenetic analysis of the sulfate reducing bacterial communities of two contrasting benthic sites in the upper estuary of the Great Ouse, Norfolk, UK. FEMS Microbiol Ecol 24:333-342

Van Heukelem L, Thomas CS (20011) Computer-assisted high-performance liquid chromatography method development with applications to the isolation and analysis of phytoplankton pigments. J Chromatogr A 910:31-49

Verity PG (2002) A decade of change in the Skidaway River estuary. I. Hydrography and nutrients. Estuaries 25: 944-960

Wetz MS, Lewitus AJ, Koepfler ET, Hayes KC (2002) Impact of the eastern oyster Crassostrea virginica on microbial community structure in a salt marsh estuary. Aquat Microb Ecol 28:87-97

Submitted: February 9, 2006; Accepted: September 5, 2006

Proofs received from author(s): November 15, 2006 